\title{
EL VACÍO Y SU FRONTERA: LA BÚSQUEDA DEL OTRO LADO EN DOS IEXTOS ARGENIINOS*
}

\section{Rita Laura Segato \\ Universidade de Brasília - Brasil}

Resumo: Toda representação de uma paisagem inclui uma narrativa sobre as marcas nela inscritas pelo povo que a habita. O discurso sobre os cenários da nação é sempre discurso sobre a história. O cinema contemporâneo, cumprindo com o papel que antes preenchera a pintura histórica e o paisagismo, rende-se também a essa premissa. Assim, a paisagem que serve de cenário à filmografia argentina contemporânea tem, no horizonte, uma fronteira sempre descrita como intransponível. Este tema da claustrofobia inerente à paisagem nacional coincide com o de outros discursos de "busca do outro lado " por uma abertura de respiração e renovação, como, por exemplo, o dos agentes que re-introduziram na argentina, a partir dos anos 60, a religião africana a partir do Brasil.

Palavras-chave: cinema, nação, paisagem.

Abstract: Any representation of a landscape includes a narrative about the imprints left by its inhabitants on it. Discourse on the scenarios of the nation is always discourse on history. The cinema of our days, fulfilling the role of historical painting and landscape painting in the past, yields to this principle as well. Therefore, the landscape that serves as scenario for the contemporary Argentine filmography has,

* Este texto será presentado en el Seminario Internacional Fronteras, naciones e identidades que se realizará en el IDES (Instituto de Desarrollo Económico y Social) en Buenos Aires, durante los días 26, 27 y 28 de mayo de 1999. Agradezco a José Jorge de Carvalho porque elaboré en diálogo con él el tema de la asfixia territorial en el cine argentino y por su auxilio en la formulación de la idea del cine como texto nacional. Agradezco a Claudio Spiguel porque hace años escucha y entiende mi percepción de las representaciones del territorio argentino y me aportó la valiosa información que ayuda a fundamentar este trabajo con una perspectiva de profundidad histórica, así como también varios datos sobre películas argentinas. Agradezco a Pedro Paulo Gomes Pereira porque me ayudó a reflexionar sobre el papel del sertão interior en el cine brasileño. Y a Ondina Pena Pereira por su comentario sobre Terra Estrangeira. Toda autoría es co-autoría, pero hay casos en que esto es más verdadero. 
at its horizon, a frontier always described as an unsurpassable barrier. This theme of claustrophobia as inhering in a national landscape coincides with other discourses of a "search on the other side" for a breathing escape and a renewal, as, for example, that of the agents who re-introduced the African religion in Argentina, since the 60', importing it from Brazil.

Keywords: cinema, landscape, nation.

\section{Viñeta}

En un inspirado ensayo que lleva el título "Telling Tales on Canvas: Landscapes of Frontier Change" ("contando cuentos en la tela: paisajes de la transformación de la frontera”), el historiador William Cronon analiza con sensibilidad notable el cuadro the Thomas Cole "The Oxbow (the Connecticut River near Northampton)”, de 1836. En este paisaje de la región central de Massachusetts, donde la presencia humana es un detalle marginal en la naturaleza, la intención del autor se nos presenta como eminentemente realista, y creemos ver en su montaña y en su río una "montaña real y un río real” que “casi podríamos visitar si así quisiéramos hacerlo”. Sin embargo, advierte Cronon, a pesar del despliegue pictórico de una naturaleza casi en estado puro, estamos frente a una narrativa histórica, más una historia sobre la frontera.

Hacia la izquierda, está el el terreno inculto que el mismo Cole anticipó como tema central del arte americano. Una gran tormenta acaba de pasar. Sus nubes oscuras nos recuerdan el espantoso poder de la naturaleza salvaje. [...] Un árbol reclinado empuja nuestros ojos hacia abajo de las nubes tormentosas [...]. El árbol nos lleva, a su vez, a la ladera rocosa [...] Si la mitad izquierda de la pintura representa el terreno inculto, la mitad derecha representa la civilización. Un paisaje pastoril ha emergido a lo largo de los bancos de este río, el Connecticut. A vuelo de pájaro podemos fácilmente relevar las líneas serenas del campo próspero y cultivado. Ovejas pastan abajo a la derecha, la cosecha de maíz se seca en un campo vecino, y podemos hasta completar los minúsculos contornos de unos pocos pastores, chacareros y barqueros en sus faenas - faenas que son, de hecho, el verdadero tema de esta pintura. (Cronon, 1992, p. 40).

Y así, conducidos por la lectura de Cronon, vamos percibiendo que el paisaje aparentemente ingenuo traza un comentario en clave estrictamente 
artística sobre el progreso, el futuro y la frontera: "Mirando, distante, el paisaje todavía inculto, el ojo de la mente es capaz de ver lejos en el futuro", escribía en un ensayo Cole el mismo año (citado por Cronon, 1992, p. 41). Este discurso visual sobre el territorio nacional y su paisaje es aquí un discurso sobre la frontera en movimiento. Se trata de una frontera en expansión que, a medida que avanza, instala, para románticos como Cole, un sentimiento de pérdida que contrasta con la contabilidad del lucro que produce.

$\mathrm{Al}$ escribir de esta forma, Cronon se agrega a una larga tradición de autores norteamericanos para quienes la pintura de paisajes es pintura histórica o, de forma todavía más extrema, donde toda representación pictórica del territorio es una comentario sobre la nación y su historia y, como tal, un discurso sobre la frontera - la historia de la frontera de expansión hacia el oeste, como es sabido, es una delas narrativas centrales de la historiografía norteamericana. Por lo tanto, discurso (visual) sobre el territorio es, aquí, discurso sobre frontera y documento histórico, en el sentido amplio en que inscribe la perspectiva de una época en relación al territorio nacional y sus objetos, manifiesta un proyecto, diseña un futuro e consagra la memoria de un presente que rápidamente se transforma en pasado, en el caso de los Estados Unidos, bajo la forma idealizada de una naturaleza de esplendor y plenitud irrecuperables. (ver, por ejemplo, Novak, 1979, 1980; Boime, 1991).

Al detenernos un poco más en este enunciado, podemos proceder a preguntarnos, entonces, por las posiciones relativas de los actores que participan en la composición del cuadro histórico en que se ha convertido el paisaje inicial. Parece entonces que el artista que fija e inscribe la escena desempeña el papel de etnógrafo, pero de un etnógrafo participante, que relata, inscribe y al mismo tiempo construye la relación de un pueblo con su ambiente, enfatizando la transformación de ese ambiente en escenario del drama histórico. Si, por un lado, este etnógrafo-artista, comenta las transformaciones de la naturaleza o el significado de la misma para un determinado pueblo, por otro lado, también homologa documentos que instituyen la relación de un pueblo con un paisaje como horizonte estable, monumento y referencia de la nación. Es en este último sentido que el paisaje, poblado de monumentos culturales o mera naturaleza de una nación - su geografía artísticamente representada -, se funde indisolublemente con su auto-percepción histórica y la representación de los monumentos naturales ocupa el lugar de los monumentos del pasado 
histórico en la imaginación nacional cuando éstos últimos no existen (Gerdsts, 1988, p. 68).

\section{Primer texto: el cine argentino contemporáneo}

En nuestros días, es el cine que realiza esa tarea historiográfica de diseñar el paisaje en el que un pueblo se instala. Este paisaje es nada más y nada menos que un territorio nacional, marcado por una historia propia y, también, a veces, puede aludir a una frontera, que permanece implícita como cerca o cerramiento exterior, como en el caso del cine argentino contemporáneo, según intentaré mostrar, o como frontera interior inalcanzable, siempre inacabado proceso de interiorización y búsqueda hacia adentro, tan característico de las obras primas del cine brasileño de todos los tiempos.

En el caso del cine, se ha dicho que constituye un medio capaz de comportarse como historiografía visual en movimiento (Rosenstone, 1995) y, por lo tanto, entre las artes, viene a desempeñar el papel anteriormente reservado a la pintura histórica, incluyendo en este género, como vine defendiendo hasta aquí, el paisajismo y las representaciones pictóricas del territorio de un pueblo particular. Lo que vemos, en el cine, es la acción de los personajes estableciendo una relación con un territorio que se transforma en escenario al mismo tiempo geográfico y moral, una geografía históricamente marcada, impregnada de sentido, afecto e ideología. Lo que se dice sobre ese territorio y lo que se dibuja en él, a su vez, es discurso sobre la historia. En este sentido, el paisaje no es simplemente el marco de la vida de una sociedad, la moldura de un conjunto de formas de sociabilidad pero, como el antropólogo lo ve, un texto inscripto por un pueblo que es, a su vez, quien tiene su llave de lectura - "la caja negra del paisaje requiere ser 'abierta’ y su contenido expuesto a la vista” dice Eric Hirsch en su introducción a una colección de ensayos sobre antropología del paisaje. Este el es texto local que el cineasta reedita, en una segunda inscripción deliberada, como diría Weber, en una interpretación de segunda mano.

Pero más que local, por sus condiciones de emergencia dentro de un campo interlocucional así como de existencia material y dependencia institucional, el cine es siempre una tradición nacional y sus escenarios, aun cuando se desplacen al extranjero, hablan de una óptica nacional sobre el territorio. 
En cuanto texto, establece relaciones con otras textualidades nacionales - literarias, historiográficas, pictóricas (sobre esta última relación entre una pintura de paisajes nacionales y el cine ver el bello ensayo de Angela Dalle Vacche sobre el paisaje romántico alemán en el cine expresionista del Nosferatu de Murnau, en Dalle Vacche, 1996). Y aun cuando el texto utilizado no sea nacional, será siempre traducido y reinterpretado dentro de una perspectiva nacional reconocible (por ejemplo, cuando Bertolucci filma La Estratagema de la Araña, el cuento de Borges gana como escenario un pueblo italiano y un fragmento de la historia de ese país).

Son varios los materiales culturales que se articulan en la confección de una película: novelas, cuentos, obras de teatro, interpretaciones contemporáneas de episodios históricos, estilos de vestuario, cultura corporal, acento, música, paisajes con sus motivos geográficos o urbanísticos emblemáticos, resultando siempre, como dije, en una re-inscripción de un conjunto de textos previos, que son así reciclados. Es por esto que puede decirse que las mediaciones del proceso de creación cinematográfica son de un orden más complejo que las de los géneros puros, lo que necesariamente implica en una combinación de principios culturales amplios como subtexto de cada película. Literatura, historia, geografía, artes plásticas, música, danza y gestualidad, textos provenientes de todos eses campos, constituyen la materia prima para la producción cinematográfica, y con su trama intertextual, fijan una representación eminente del espacio nacional. Será por eso que la tendencia de los analistas contemporáneos es hacer referencia constante, más o menos teorizada, a cinematografías nacionales.

Ella Shohat y Robert Stam, en su Unthinking Eurocentrism. Multiculturalism and the Media, a pesar de utilizar las categorías generales de “Occidente” y "Tercer Mundo", hacen referencia inevitable a las tradiciones nacionales - egipcias, iraníes, etc. - y soslayan la existencia de regularidades y constantes idiosincráticas de los universos nacionales, aun reconociendo la hibridez de sus productos:

En su calidad de productos de industrias nacionales, producidos en lenguajes nacionales, retratando situaciones nacionales y reciclando intertextos nacionales (literaturas, folklores), todas las películas son, por supuesto, nacionales [...], justamente de la misma forma que todas las películas proyectan imaginarios nacionales [...]. Cineastas del tercer mundo se ven a sí mismos como parte de un proyecto nacional. (Shohat; Stam, 1995, p. 285). 
De la misma forma, Rosenstone, en su propuesta de un cine histórico como nuevo género historiográfico, afirma que, a menudo, las producciones locales constituyen "contra-historias de las usuales narrativas nacionalistas", donde "en muchos casos, este tipo de historiografía visual anticipó campos en la historiografía escrita” (Rosenstone, 1995, p. 5). A su vez, Fredric Jameson, en sus escritos más recientes sobre una geopolítica de la estética, a pesar de su énfasis en que la totalización mundial es la referencia de toda representación como consecuencia del proceso de globalización contemporáneo, continúa situando las películas que comenta en sus horizontes nacionales como elemento significativo, particularmente al tratar de producciones no norteamericanas:

La narrativa hoy (o por lo menos la narrativa fuera del super-estado) [...] colapsa (conflates) ontología y geografía. [... la la alegoría permite que el más aleatorio, minucioso o aislado de los paisajes funcione como como una maquinaria figurativa en la cual las cuestiones relativas al sistema y su control sobre lo local emergen y decaen incesantemente. (Jameson, 1995, p. 4-5).

Aunque la cuestión nacional pierde, en este análisis, su centralidad para la cuestión del sistema global, la geografía local y nacional, como índice visual de una geopolítica, no puede, todavía, ser descartada. Por su parte, Hamid Naficy habla de un "cine con acento" aun en los casos de directores exilados que, a pesar de trabajar ya con equipos de técnicos y actores del país de residencia, imprimen una inflexión de su nacionalidad de origen filmando fuera de él (Naficy, 1999).

$\mathrm{Al}$ abordar la cinematografía argentina dentro de esta perspectiva que afirma que el cine es un discurso nacional, es posible afirmar que, en ella, el tema territorial es recurrente. A partir de los años ochenta, la representación de un territorio cubierto por las aguas (como en El viaje, de Solanas, 1987, o Últimas imágenes de un naufragio, de Subiela, 1989), desierto, deshabitado (El Viaje) o atravesado por carreteras que no parecen ir o venir de ninguna parte (Sur, de Solanas, 1987, Una sombra muy pronto serás, de Héctor Olivera, 1989, Caballos Salvajes, de Marcelo Piñeyro, 1995) se transforma en el escenario habitual de la narrativa, a menudo desolado escenario de una fuga como única trama. Pero, por encima de todo, un cine cuyos personajes siempre buscan una salida o, en algunos casos, un re-ingreso: venir de fuera, estar yendo, o ambas situaciones transformándose en prácticamente las dos puntas de un único periplo sin sentido como en Una sombra muy pronto serás. El juego del afuera y el adentro es su motivo recurrente, su tema emblemático, que confiere 
centralidad a la frontera como marca de la nación. Aunque de formas muy distintas, ser un extranjero inescrutable, que viene de otro planeta, en Hombre mirando al sudeste, de Subiela (1986) o un extranjero en el interior de su propia nación, como en Un lugar en el Mundo, de Adolfo Aristarán (1994) o La Deuda Interna de Miguel Pereira (1986), pero siempre la cerca delimitando un territorio de atmósfera enrarecida, frontera geográfica y simbólica del país, es un hito notable en el horizonte argentino, tal como representado en el texto cinematográfico de las últimas dos décadas.

El clima de encerramiento y asfixia y la constante alusión a un vacío interior al que se contrapone un lado de afuera más luminoso se repite: es la frontera, en este conjunto de narrativas, el portón de la utopía para los argentinos. Y es alejándose, buscando alcanzar, por alguna carretera, el otro lado, que los personajes jóvenes de El Viaje y Caballos Salvajes consiguen comprender, alcanzar una visión iluminada.

En el punto crítico de la trama de Últimas imágenes de un naufragio, de Subiela, cuando el personaje central toma la decisión de cambiar de vida y precisamente con la intención de convencerlo a abandonar su pacata rutina de vendedor de seguros y escritor en los ratos libres para transformarse en el mentor intelectual de sus robos, su interlocutor le sugiere:

- Pensá buenos afanos y nos salvamos todos. Le damos la guita a Mario para que termine el avión. Vos te vas con Estela al Brasil. Playas... Sol... Imagináte terminando ahí la novela! [...] Y yo me las tomo también a recorrer el mundo. El planeta es tan grande, Robertito, y uno encerrado en esta mierda, hermano! Nunca te van a pagar tanto por tu imaginación! Te estoy ofreciendo la liberación, macho, eh!

Otros diálogos también son representativos de este espíritu. En El Viaje, cuando el terremoto atraviesa el Colegio con escenografía de cárcel, alegoría del país vacío y autoritario, alguien grita: “Abandonen la jaula”, y ninguna frase suena tan categórica y heroica como el "Muchachos, me voy" del roquero joven. Asume visos de emblema la placa apostada en la punta sur de Santa Cruz, donde nadie pasa y el continente ya se acaba, que le anuncia a Martín, en la misma película: "New Patagonia - São Paulo - Caracas".

No es de extrañar que en El lado obscuro del Corazón, de Subiela (1992), el protagonista viva y ame intensamente solo del otro lado del Rio. O que la única esperanza posible para el hijo que va a nacer, en Pizza, birra, faso, de 
Bruno Stagnaro y Adrián Caetano (1998), quede también al otro lado: "Y si nos vamos al Uruguay?”, es la frase que queda resonando, y la última escapada es para intentar alcanzar con vida la balsa que cruzará el Rio. Un elemento más para que percibamos, en un vislumbre, que se trata de un país cuyo centro mismo se encuentra situado en una frontera: el puerto. Y que si es generalmente característico que las naciones del nuevo mundo tengan su capital en la costa, solamente Buenos Aires, más que capital centro del mundo, se apoya en la frontera pluvial del Rio de la Plata, "el otro lado” o el más allá del confín constituyendo uno de los centros y una referencia constante en nuestra composición del texto territorial.

A este hecho podría ser que aludiese, si aceptamos su intención irónica, el cuento de Borges “El Congreso”, que sitúa en un páramo del confín de la región del Plata, en una estancia ganadera y vacía del borde entre el Brasil y el Uruguay - ambas naciones del "otro lado" - su utópica y caricaturesca convención de las civilizaciones del mundo, donde los representantes de todos los saberes vendrían a encontrarse.

De hecho, la extraña paradoja del país que tiene el centro en un confín tiene raíces temporales profundas. Algunos flash-backs sirven para mostrarlo. La fundación definitiva de Buenos Aires por Garay vino desde dentro, como consecuencia de una colonización que "bajó" desde el Lima y desde Asunción "buscando puertas al mar”. Buenos Aires fue, así, por mucho tiempo, la última frontera del imperio español. Puerto cerrado, vigilado, del contacto clandestino con portugueses, holandeses, franceses y británicos por cien años. Fueron, en este período, notorias las formulaciones de Matienzo, Oidor de la Audiencia de Charcas que, dando eco a las peticiones de distintos sectores locales - del Tucumán al Alto Perú - clamaba por la necesidad de "abrir puertas a la tierra”, o sea, abrir Buenos Aires al comercio y a las comunicaciones con España, rompiendo el camino obligado de las flotas: Caribe - Panamá - Pacífico - Lima - Alto Perú - Potosí - Río de la Plata. El tema de abrir el puerto será, desde entonces, fundacional para la nación.

Es tardíamente, a partir del siglo XVIII y durante todo el siglo XIX que tiene lugar el lento desplazamiento del centro de gravedad político, comercial, demográfico, del territorio desde el Alto Peru para el litoral y la costa de Buenos Aires. Este proceso es paralelo y relacionado al proceso de apertura del puerto - primero con y hacia España, en el siglo XVIII y, después de la revolución, con Europa. A esto se suma el registro histórico e ideológico de un Buenos Aires frontera en múltiplos sentidos: primero de un interior que 
se expandió hasta ese litoral que conectaría con la Metrópoli; después, con Europa; y hasta la primera mitad del siglo XIX, con el indio - un estrecho “corredor porteño” llevaba al mar. Esta doble frontera: con el exterior y con el indio, era doble también en el sentido de que abría y cerraba el territorio marcando el punto ambivalente de ruptura y contacto. La frontera con el indio se transforma después, a partir del siglo XIX y bien entrado el XX, en la frontera con el interior-otro, con el inmigrante de adentro y de América Latina: llegar del interior es tocar la puerta de entrada al mundo, único puerto de entrada y de salida de los vuelos a Estados Unidos y Europa.

Sólo una percepción del espacio tan arraigada en el tiempo y luego reforzada por los gobiernos autoritarios podría permitir la recurrencia pasmosa de este tema en el cine nacional. La comparación con el cine brasileño nos lleva a la conclusión de que la frontera ocupa lugares distintos en la imaginación nacional de Brasil y la Argentina. Si la geografía fuese imaginaria y la cartografía incluyera los trayectos preferenciales de un pueblo, el pueblo Argentino se estaría dirigiendo siempre a una frontera exterior distante e intransponible, y el brasileño dándole la espalda. Si en el cine brasileño el espacio nacional se abre hacia dentro, en el cine argentino la única abertura de respiración del espacio nacional es hacia el exterior.

En su lectura de la película Bye bye Brazil de Cacá Diegues (1980), que narra la internación territorial de sus personajes en una caravana de actores en busca de un futuro fuera del proceso letal de modernización, Robert Stam, João Luiz Vieira e Ismael Xavier se refieren al interior del país como "el sitio de la esperanza perenne” (Johnson; Stam, 1995, p. 420). La misma peregrinación hacia un interior sacralizado como fuente inextinguible de sentido, razón y libertad es retratada en el clásico del Cinema Novo de la década del 60: Deus e o Diabo na Terra do Sol de Glauber Rocha (Gomes Pereira, 1997a, 1997b). Y, coincidentemente, el tema resurge en 1997 con la exitosa película Central do Brasil, de Walter Salles Jr., donde se narra "el retorno al sertão como alegoría nacional de reposición de valores” (Xavier, 1998/1999, p. 88), el proyecto de humanización y salvación se realiza, una vez más, hacia adentro, lugar utópico que llama con el espejismo de la felicidad. Es en el interior que las narrativas brasileñas sitúan la perspectiva de futuro.

En una película anterior, Terra Estrangeira, Walter Salles explora esa gesta recurrente de interiorización en el cine brasileño. Expresa, entonces, el extrañamiento y la alienación de sus personajes como habitantes de un país en el que se sienten extranjeros. Al lanzarse en búsqueda de una reserva 
simbólica interior buscan un horizonte donde su identidad transida y claudicante pueda encontrar amparo. Una patria perdida o todavía no encontrada, un refugio escondido en el corazón del territorio

Si en Brasil la internación lleva en dirección a una promesa de intensidad y revelaciones desconocidas, en la imaginación Argentina la internación lleva, campo a traviesa de un espacio desolado, desocupado e inhóspito, a una frontera donde el estado y la sociedad libran su última gran conflagración, llegan al límite de su tenso pacto. El ritual escolar, cuja liturgia patriótica aparece en tono de sátira, en toda la magnitud de su absurdo, tan bien descripto por Solanas en El Viaje, podría ser justamente la clave de la transposición del paisaje en historia. La frontera percíbese, así, como el límite preciso donde la sociedad y el estado se confrontan.

Quien ha visto, como yo, la liturgia escolar en un pueblo fronterizo de la puna percibe el proyecto nacional arquitectado hasta el detalle por el estado central en toda su extraordinaria eficacia: el ritual cívico-patriótico en las escuelas idéntico en el centro como en las márgenes, calco exacto de una matriz concebida minuciosamente, con su izamiendo de la bandera, sus filas de niños vestidos de blanco, su silencio electrizado, su "Salve Argentina", hacen que el primero y el último mojón sean idénticos en su calidad de signos, formalmente idénticos. Resulta claro entonces el papel nacionalizador de la escuela, no meramente, como a menudo se ha enfatizado, en el sentido de nacionalizar la sociedad (Solari, 1988, p. 136-137, 198 ss.; Tedesco, 1986) o crear una mentalidad de nacionalismo territorial (Escudé, 1987) sino también, notablemente, de inscribir el territorio de forma indeleble con los signos de la nación. La otra gran alegoría territorial del control totalizador del estado nacional es, como lo describe magistralmente Jorge Salessi, la duplicación subterránea de la ciudad de Buenos Aires en sus cloacas como parte del proyecto higienista de fines del siglo XIX, así como la inspección sanitaria de todo el territorio nacional (Salessi, 1995).

El cine parece mostrar que somos argentinos como Buñuel era católico: en tono de parodia, como pura negatividad. Es esta identidad negativa que nos hace lo que somos. El hombre común está condenado a habitar el espacio interior como un destino maldito creado por otros, inventado por una inteligentsia político-letrada que monopolizó la producción de los discursos administrativos y literarios del país desde el siglo XIX y totalizó el territorio (Viñas, 1982, p. 149). Cambiarla, colocaría en situación de riesgo todo el andamiaje de la identidad argentina. Sin embargo, es propicio aquí recordar que, posiblemente, el único cineasta cuyos temas independen de una referencia explícita al 
"lado de afuera” es también el de inspiración más popular: Leonardo Fabio. Mostrando en sus personajes y en sus narraciones un mundo que, a pesar de sufriente, se basta a sí mismo.

Por lo demás, el tema del adentro y del afuera, del volver y del partir se repite hasta el cansancio en las tramas más diversas: Made in Lanús; Mirta, de Liniers a Estambul; Diario de un Cuento; Fuga de cerebros; Cómplices; Sus ojos se cerraron; Amigomio; entre otros títulos que podría aquí posiblemente mencionar.

Pero es Camila, ya un clásico de Maria Luisa Bemberg sacralizado por los catálogos y los críticos (1984), la película paradigmática de lo que identifico como un leit-motif nacional: un territorio como espacio de fuga, una nación como jaula y una frontera que separa de la salvación. El Brasil representa, aquí, una vez más, el espacio del Otro.

Los personajes de la historia son la joven Camila y el cura Ladislao. Camila, de familia oligárquica, padre rosista, pero heredera del estigma de la Perichona, antigua amante de Liniers y pro-francesa antes de la revolución de mayo, es asidua lectora de las obras recién llegadas al Río de la Plata que el librero le provee, conocedora del "Contrato Social” de Rousseau y ávida por un espacio de respiración en el ambiente represivo de la tiranía de Rosas y de la familia oligárquica patriarcal y despótica.

La trama está dada por el amor interdicto entre los dos, y el escenario, por la dictadura de Rosas, gobierno omnímodo de los terratenientes que, a pesar de su vinculación comercial con Gran Bretaña, pregonan cerrazón antiliberal y xenofobia tradicionalista. El romance con el curita es usado en ambas bandas del rio. Por los rosistas, para demostrar la influencia perniciosa de las ideas extranjeras y de los unitarios. Por los viejos exilados unitarios en Montevideo - tan aristocráticos como los rosistas, pero "ilustrados” y cosmopolitas - como expresión de la degradación moral de la dictadura. Los análisis convencionales, como el de David Foster (1992), se centran en el tema de la historia de amor en clima represivo, donde el cura representa la sociedad patriarcal y un camino sin salida para la búsqueda de libertad que Camila representa. Yo percibo, desde mi óptica territorial, algo más.

Ya en los primeros momentos de la película, Camila lee, de forma premonitoria, un texto de Echeverría: "No hay cosa más triste que emigrar. Salir de su país violentamente, sin quererlo, sin haberlo pensado, es un tormento que nadie puede sentir sin haberlo por sí mismo experimentado. La emigración es la muerte". Transformados en amantes, huyen y se refugian en la Provincia de Corrientes, donde viven como maestros de escuela y donde finalmente son 
descubiertos. La única salvación, según les comunica un soldado que tiene orden de arrestarlos pero quiere darles una última oportunidad, es cruzar la frontera, pasar al Brasil:

Soldado: en la puerta de su casa va a encontrar dos caballos con provisiones. Brasil no está lejos. No pierdan tiempo. El amanecer se acerca y entonces voy a tener que cumplir con mi uniforme."

Camila: Gracias. (Encuentra Ladislao en la Iglesia rezando. Amanece.)

Ladislao: Yo siempre seré Gutiérrez. Perdonáme.

Camila: Yo lo quise así, no me arrepiento de nada.

Ladislao: Yo tampoco. Pero no puedo con Él (refiriéndose a su Dios)

Si el clima autoritario permite una interpretación literal del territorio como opresivo, asfixiante, la recusa de Ladislao a partir dice más: habla de una sociedad atrapada en el territorio, de la intransponibilidad de una frontera que no es solamente geográfica sino también simbólica, donde la geografía es el índice de una ontología. Cruzarla, significa colocar en riesgo la propia identidad, el texto al cual el sujeto se aferra desesperadamente para negociar su propia posición. Camila podría hacerlo, el cura no, porque su identidad se encuentra profundamente comprometida no solamente con la ley paterna (como Foster lo lee), sino también con el orden ideológico de la propia nación en cuanto tal, del cual él mismo no es, como sacerdote católico, sino uno de sus emblemas. El coheso y sofocante espacio nacional tiene su metáfora, aquí, en la imposibilidad del amor en libertad. La captura de los amantes es una alegoría de segundo grado de un territorio sofocado por una frontera intransponible, a su vez ícone de la nación. Me parece ser ésta una "escucha" posible de lo dicho por Ma. Luisa Bemberg, en la parte más codificada e inconsciente de su enunciado.

\section{Segundo texto: la búsqueda de los espíritus "del otro lado"}

Es esta misma ansiedad de encerramiento, cuya alegoría es el territorio cercado, que he tematizado en artículos anteriores, intentando siempre hacer sentido de la introducción de las tradiciones religiosas afro-brasileñas en Argentina como la búsqueda de la abertura del territorio cerrado y homogéneo de la cultura nacional para incluir fragmentos del Brasil, abrir entradas a la influencia africana. Homogeneidad cultural y asfixia territorial me parecen ser términos de una relación de mutuo espejamiento, donde el proyecto de 
totalización nacional para el territorio y la cultura tuvo una eficacia singular. El gancho con genealogías de culto afro-brasileiras, a través de un emparentamiento ritual, introducía, a los ojos de mis informantes, una abertura para la diversidad, un espacio de respiración.

En efecto, los adeptos de la religión afro-brasileña que entrevisté en Buenos Aires, aun siendo blancos de descendencia netamente europea o, a lo sumo, con un mestizaje indígena, afirmaban insistentemente que "la raíz africana había existido en la Argentina pero había sido destruida” y era necesario reintroducirla desde el Brasil (Segato, 1991). Una alusión clara, según argumenté a la luz de una serie de evidencias, al proceso de formación de la nación como arquitectura de un territorio cultural homogéneo y cerrado a que vengo refiriéndome.

El discurso de mis informantes no se amparaba abiertamente en la necesidad de abrir una brecha nueva en el espacio nacional, sino de crear un signo para las subjetividades que ya existían y que no encontraban registro, nicho, expresión en los discursos dominantes en la autoconsciencia nacional. Por eso hablaban con tanta pasión del negro, de la raíz africana, como signo de una subjetividad que había estado presente, que fue expatriada y de la que sentían la falta.

Una vez esto claro, es posible recordar que aquello que fue expatriado puede ser repatriado. Y esta afirmación me lleva de vuelta a la cuestión de lo que podrían estar buscando el Pai Julio de Obá, Teresa Fernández o el joven Gustavo cuando adhirieron al culto: que es lo que estarían buscando en el Brasil? En que consiste esa 'raíz' que dicen perdida pero cuyo espíritu sobrevive? Algo los lleva a repatriar ese sujeto, reencarnarlo, a traer de vuelta ese otro pródigo, producirse, agenciarse en su historia. En fin, reintroducir los conocimientos - en este caso basicamente religiosos, pero que implican también un tipo de sociabilidad y un ethos -, la cultura, en cuyo seno podría volver a darse aquel modo de subjetivación. De hecho, el proceso de supresión ideológica del negro y el de su actual reintroducción se amplían metonímicamente en el discurso de mis informantes y pasan a hablar de la supresión de toda alteridad y de la repatriación de la misma. (Segato, 1991, p. 260. Mi traducción del portugués y mi énfasis añadido).

Del doble movimiento de lo por mí apuntado en el artículo que cito en el sentido de encontrar un nicho diferenciado dentro de la nación para subjetividades minoritarias, al mismo tiempo trabajando para nacionalizar " $\mathrm{La}$ 
Religión”, como sostiene Alejandro Frigerio (1993), resulta la tentativa de abrir el territorio para las marcas, en el mismo, de esas subjetividades. La figuración de ese proceso pasa, en el discurso de los adeptos, por la transgresión de la frontera. Su transposición, el reingreso y su abertura.

Y eso es lo que comprueba el relato de una de las primeras entradas de la espiritualidad afro-brasileña en el territorio argentino, reconstruido a partir varios testimonios de primer y segundo grado y de un período de investigación de campo en Santana do Livramento - frontera brasileño-uruguaya por donde se operó el pasaje a que haré referencia. Narro no sólo las informaciones que recogí sino también los detalles del proceso a través del cual exhumé esta historia en el artículo "Frontiers and Margins: The untold story of the Afro-Brazilian religious expansion to Argentina and Uruguay” (Segato, 1996. A salir también en portugués en el próximo número de la revista Religião e Sociedade, Río de Janeiro, 19/1, 1999).

Si los relatos oficiales de esta historia muestran un conjunto inicial de personajes interesados en expandir su espiritualidad, su capacidad de cura y, en fin, su cosmología, instados por experiencias extáticas espontáneas e inspirados por viajes más o menos turísticos o períodos de residencia en el Brasil (como en el caso de mãe Nélida de Oxum, que abrió el primer tempo de "Religión" registrado en el país en 1966; o mãe Gladys de Oxum, dueña de un terreiro ya muy consolidado y rico, frecuentado por miembros de las familias Peralta Ramos y allegados de Fortabat, según me consta), otra vía de entrada, submersa y reveladora, parece hablar más explícitamente de la búsqueda de una abertura para espacios de subjetividad que solo pudo formularse como "reintroducida", apelando al "lado de afuera" y forzando una abertura del territorio para incluirla.

En los años cincuenta, el paso privilegiado del tráfico comercial entre Brasil y los países del Plata era la única gran urbe en frontera seca, conglomerado formado por Santana do Livramento, del lado brasileño, y Rivera, del lado uruguayo. La frontera en ese punto se vuelve difusa, porosa, y una línea de baldosas más obscuras es la única marca que separa el mundo portugués del castellano. Ciudadanos de "doble chapa" abundan, todas las familias tienen genealogías entreveradas, todas las biografías tienen ambos lados como escenario y es usual ver parejas conversando en alta velocidad, cada uno en su lengua. Los más letrados llegan a afirmar sin resquicio de dudas que el General Borges de Medeiros, que presta su nombre a la avenida central de Santana, es un ancestro del Borges porteño. 
Allí "la noche" era agitada en los años 50 y florecían una variedad de locales como consecuencia de la densidad de las carreteras antes de la construcción del Puente de la Amistad en el punto tripartito de Iguazú. Entre ellos el burdel más famoso, llamado "El Chalet Verde”, era administrado por una mujer oriunda de una familia patricia de políticos y fazendeiros de Rio Grande do Sul: Ana Aramita Brun, que cambió su nombre por el de "Erna Brun". Erna Brun tenía un hijo, que criaba a distancia en Montevideo, y era una "mujer-hombre” que se envolvía en historias pasionales con algunas de las prostitutas que venían a trabajar en su Casa. A su casa, frecuentada por fazendeiros y comerciantes, de la región o en tránsito, no solamente iban a trabajar las mejores mujeres de la región sino que era el polo de atracción de un grupo de travestis argentinos y uruguayos, que buscaban en ese ambiente fronterizo y, sobre todo, brasileño, un espacio de descontracción para su orientación sexual minoritaria.

En Santana había, también, un terreiro hoy legendario, perteneciente a Mãe Teta (fallecida en 1997 con más de noventa años). Inicialmente un terreiro de caboclos o espíritus de la tierra, brasileños; posteriormente, convertido también en terreiro de batuque, para el culto de los orixás africanos de la casa. Mãe Teta y Ema Brun cultivaron una amistad que duró hasta el fin de la vida de esta última, al punto que llegó a iniciarse en el culto como filha de santo de la primera, y mandó construir, a la entrada del Chalet Verde, una casa de Bará para cuidar la puerta, y un cuarto para hacer obrigações - los sacrificios a las entidades y los dioses que el culto exige. Allá iba Mãe Teta a oficiar periódicamente. Y allí la conocieron Mara, Víctor, Roberto, los travestís de la Casa, hoy todos pais de santo.

Mara dejó la vida "de la noche” para abrir, según la versión de esta historia a que aquí me apego, la primera casa de santo en Buenos Aires. Unos dicen que allí solamente se leía el oráculo de búzios al comienzo. Otros, que se realizaban pequeñas obrigações. Pero la conversión de estos primeros agentes, pioneros de la introducción de las tradiciones religiosas afro-brasileñas en Argentina habla más alto de una búsqueda que sugiere otras repercusiones, que implica una superposición de otros significantes sociales. Los detalles de su transformación en sacerdotes de una religión brasileña que cultúa, entre otras entidades autóctonas, espíritus de prostitutas y rufianes y abre espacio para la experiencia de un travestitismo extático, así como la decisión de importar para las ciudades del Plata este nicho de identificaciones 
posibles abriendo un hueco formal, ritualizado, para una subjetividad antes sin expresión, manifiesta claramente el sentido de la búsqueda de este grupo más allá de la frontera, la lucha por introducir significantes de ruptura en la cohesión moral y cultural del territorio nacional. Trazar un emparentamiento, a través del vínculo ritual férreo, obligatorio, entre las casas originarias de allá y las casas de acá, deja la frontera abierta de forma definitiva. Formar linajes religiosos, famílias de santo (porque es así que funcionan estos cultos), genealogías con ramificaciones que hoy ultrapasan Porto Alegre y Río de Janeiro para llegar hasta Bahia, es abolir, subversivamente, la frontera política y abrir el territorio cultural. Pero lo abren no solamente para la religión y los contenidos de cultura africana, sincréticos en mayor o menor grado, sino para formas de subjetividad divergentes que no tenían inscripción en el espacio nacional. Y no se trata aquí de una coincidencia accidental, sino de una superposición de eventos que puede ser atribuida a la estructura misma de la gran tradición afro-brasileña, con su peculiar régimen de construcción de los géneros, su ontología impregnada de androginia, su foco en la ambigüedad y en las situaciones de tránsito, su característica suspensión de la fixidad de las identidades decurrente de la experiencia de la posesión, y su permanente subversión de los esencialismos (Fry, 1977, 1986; Wafer, 1991; Segato, 1995, 1998, entre tantos otros que han hablado de esa característica de la tradición a la que aludo sintéticamente aquí).

\section{Intertexlualidad, frontera y nación}

El antropólogo es un articulador de intertextualidades, un artesano que teje su discurso con fragmentos textuales preexistentes. Entrelacé aquí un conjunto de enunciados recogidos en el cine nacional y entre la gente que reintrodujo una brecha de espacio negro en la nación argentina. Encontré que ambos diseñaban un comentario congruente sobre el espacio nacional: su cerramiento sin fisuras, su carencia de líneas de fuga, de espacios de alteridad. En ambos textos, la búsqueda de una abertura hacia el exterior es un tema recurrente. Si en las fuentes cinematográficas la frontera es un hito simbólico, donde la divisa territorial es metáfora de un corte ontológico, en la segunda fuente la frontera es literal: el lugar real donde subjetividades marginales fueron al encuentro de una identidad posible y la introdujeron bajo el signo de la repatriación de un nicho civilizatorio percibido como perdido y reencontrado. 


\section{Referencias}

BOIME, A. The magisterial gaze: manifest destiny and American landscape painting, c. 1830-1865. Washington: Smithsonian Institution Press, 1991.

CRONON, W. Telling tales on canvas: landscapes of frontier change. In: PROWN, J. D. et al. Discovered lands, invented pasts: transforming visions of the American West. New Haven: Yale University Press/Yale University Art Gallery, 1992. p. 37-87.

DALLE VACCHE, A. Cinema and painting: how art is used in film. Austin: University of Texas Press, 1996.

ESCUDÉ, C. Patología del nacionalismo: el caso argentino. Buenos Aires: Instituto Torcuato Di Tella: Editorial Tesis, 1987.

FOSTER, D. W. Contemporary Argentine cinema. Columbia: University of Missouri Press, 1992.

FRIGERIO, A. De la Umbanda al Africanismo: identificación étnica y nacional en las religiones Afro-Brasileñas en Argentina. In: FONSECA, C. (Ed.). Fronteiras da cultura. Porto Alegre: Editora da UFRGS, 1993.

FRY, P. Mediunidade e sexualidade. Religião e Sociedade, n. l, 1977.

FRY, P. Male homosexuality and spirit possession in Brazil. Journal of Homosexuality, v. 11, n. 3-4, 1986.

GERDSTS, W. H. On elevated heights: American historical painting and its critics. In: GERDSTS, W. H.; THISTLETHWAITE, M. (Ed.). Grand illusions: history painting in America. Fort Worth, Texas: Amon Carter Museum, 1988.

GOMES PEREIRA, P. P. A violência e o sagrado em Deus e o Diabo na Terra do Sol. Múltipla, v. 2, n. 2, p. 103-122, jul. 1997a.

GOMES PEREIRA, P. P. Alegorias do Brasil: uma análise de Deus e o Diabo na Terra do Sol. Revista Brasiliense de Pós-Graduação em Ciências Sociais, v. 1, n. 1, p. 151-174, 1997b. 
HIRSCH, E.; O'HANLON, M. (Ed.). The anthropology of landscape: perspectives on place and space. Oxford: Clarendon Press, 1996.

JAMESON, F. The geopolitical aesthetic: cinema and space in the world system. Bloomington and Indianapolis: Indiana University Press, 1995.

JOHNSON, R.; STAM, R. (Ed.). Brazilian cinema. New York: Columbia University Press, 1995.

NAFICY, H. (Ed.). Home, exile, homeland: film, media, \& the politics of place. New York: Routledge, 1999.

NOVAK, B. American painting in the nineteenth century: Realism, Idealism and the American experience. New York: Oxford University Press, 1979.

NOVAK, B. Nature and culture: American landscape painting, 1825-1875. New York: Oxford University Press, 1980.

ROSENSTONE, R. A. Introduction. In: ROSENSTONE, R. A. (Ed.). Revisioning history: film and the construction of a new past. Princeton, New Jersey: Princeton University Press, 1995.

SALESSI, J. Médicos, maleantes y maricas. Rosario: Beatriz Viterbo, 1995.

SEGATO, R. L. Uma vocação de minoria: a expansão dos cultos afrobrasileiros na Argentina como processo de reetnicização. Dados: Revista de Ciências Sociais, v. 34, n. 2, p. 249-278, 1991.

SEGATO, R. L. Inventando a natureza: família, sexo e gênero no Xangô de Recife. In SEGATO, R. L. Santos e daimones: o politeísmo afro-brasileiro e a tradição arquetipal. Brasília: Editora da Universidade de Brasília, 1995.

SEGATO, R. L. The color-blind subject of myth; or, where to find Africa in the nation. Annual Review of Anthropology, n. 27, 1998.

SEGATO, R. L. Frontiers and margins. The untold story of the Afro-Brazilian religious expansion to Argentina and Uruguay. Critique of Anthropology, v. 16, n. 4, p. 343-359, December 1996. 
SOLARI, M. H. Historia de la educación argentina. Buenos Aires: Paidós Educador, 1988.

SHOHAT, E.; STAM, R. Unthinking eurocentrism: multiculturalism and the media. London: Routledge, 1995.

TEDESCO, J. C. Educación y sociedad en la Argentina (1880-1945). Buenos Aires: Ediciones Solar, 1986.

VIÑAS, D. Indios, ejército y frontera. México: Siglo Veintiuno, 1982.

WAFER, J. The taste of blood: spirit possession in Brazilian Candomblé. Philadelphia: University of Pennsylvania Press, 1991.

XAVIER, I. Movimentos táticos para um tempo sem estratégias. Rumos: os caminhos do Brasil em debate (Publicação da Comissão para as Comemorações do V Centenário do Descrobrimento do Brasil), ano 1, n. 1, p. 85-88, dez. 1998/jan. 1999. 